\title{
Los medios en el ciclo de vida de los conflictos Aportes de la comunicación a la gobernabilidad en contextos de crisis
}

\author{
Sandro Macassi Lavander \\ (Pontificia Universidad Católica del Perú)
}

Recibido: 29/12/2010

Aprobado: 1/2/2011

\begin{abstract}
Resumen: El artículo aborda la incidencia que tienen los conflictos sociales en la gobernabilidad democrática, con un enfoque en el rol que juegan los medios en el recrudecimiento o la transformación de los conflictos. Se analiza cada una de las etapas de su ciclo de vida, identificando en cada una de estas los roles desempeñados por los medios en los diferentes casos de conflictos específicos. Finalmente, sostiene la necesidad de que los medios repiensen su quehacer, asumiendo nuevos roles que estén a la altura de los escenarios de crisis, lo cual facilitará la transformación pacífica de los conflictos en procesos de desarrollo y fortalecimiento de la democracia.
\end{abstract}

Palabras clave: Prevención de conflictos / periodismo / medios de comunicación / cultura de paz

\section{Media in the life cycle of conflict: Communication contributions to governance in crisis contexts}

Summary: The article discusses the impact that social conflicts have on democratic governance with a focus on the role that media plays in the resurgence and transformation of conflicts. We analyze each of the stages of the life cycle of conflicts at each stage, identifying the roles played by the media in different cases of specific conflicts. Finally, it sustains the media need to rethink their work, assuming new roles in crisis scenarios, which will facilitate the peaceful transformation of conflict in processes of development and strengthening of democracy.

Keywords: Conflict prevention / journalism / media / culture of peace 


\section{Introducción}

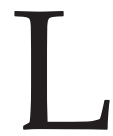

os conflictos sociales vienen flanqueando a las democracias en toda Latinoamérica. Gobiernos populistas, liberales, de izquierda o de derecha no están exentos de lidiar con movilizaciones masivas y tomas de carreteras, que presionan por una mejor redistribución y demandan un mayor acceso a los recursos, al mismo tiempo que defienden sus derechos y buscan satisfacer sus necesidades básicas, materiales, sociales y simbólicas en un mundo cambiante, complejo y globalizado.

La respuesta de los gobiernos muchas veces ha sido la intolerancia, la deslegitimación de las demandas, el desprestigio de los interlocutores y la criminalización de la protesta social. Con frecuencia se ha usado la fuerza de manera desproporcionada, con lo cual se ha minado su popularidad y se ha tirado por tierra la credibilidad de la población en su rol redistribuidor. En otras palabras, los conflictos sociales mal manejados continuamente ponen en jaque la gobernabilidad en lugar de constituirse en fuerzas transformadoras de desarrollo y cambio social.

Los conflictos sociales han existido en nuestras sociedades desde los inicios de su conformación como repúblicas. Lo que ha cambiado es básicamente la mirada y el enfoque con que se vienen abordando y analizando.
Por mucho tiempo el análisis político bipolar ha sido el lente por el cual se ha actuado y abordado los conflictos sociales. Ciertamente, las décadas pasadas dominadas por la Guerra Fría y el marxismo enmarcaron la forma de analizar y abordar los conflictos tipificándolos como "movimientos en contra del sistema" o "movimientos a favor de la acumulación de fuerzas sociales", lo cual ha reducido y deslegitimado la complejidad y legitimidad de las demandas sociales implícitas en las acciones de fuerza desarrolladas por los actores del conflicto.

En los últimos años, la mirada ha venido cambiando; lo político ya no es el único eje desde el cual se analizan (aunque todavía se actúa desde esa óptica) y se van recuperando las dimensiones económicas, relacionales y multiculturales de los conflictos sociales.

Frente a los conflictos, por mucho tiempo las ciencias sociales han subrayado que la "fractura estructural entre el Estado y la sociedad" y la "crisis crónica de la representación entre la clase política y la ciudadanía" eran las condiciones suficientes para explicar todos los conflictos emergentes. Sin embargo, estas argumentaciones no pueden esclarecer la similitud en las dinámicas y el funcionamiento que los conflictos tienen en diferentes latitudes del planeta y en países con distintos grados de desarrollo.

Recientes investigaciones han puesto el acento en que el crecimiento 
acelerado y la desestructuración social que genera el mercado están en la base de los conflictos sociales; no les falta razón, pero no explica suficientemente por qué en otras latitudes el mercado más bien ha integrado a las poblaciones y ha distendido los conflictos que por mucho tiempo han existido.

El análisis multifactorial de la naturaleza de los conflictos precisamente muestra que el crecimiento económico despierta tensiones y enfoques diferentes de desarrollo, pero opera sobre una conflictividad preexistente: tensiones y disputas territoriales dentro de las comunidades, entre las comunidades, entre comunidades y gobiernos locales y estos con los poderes fácticos en pos del acceso a recursos vitales, simbólicos y materiales.

En este nuevo escenario de conflictividad, los medios han estado presentes en todos los conflictos sociales que han emergido en América Latina. En el presente artículo discutiremos cuáles han sido los roles que los medios han desempeñado, partiendo de la necesidad de que los conflictos pueden ser transformados y conducidos a soluciones negociadas y constructivas que aporten a la gobernabilidad, en lugar de salidas violentas que destruyen el tejido social y generan resentimientos que perduran en el tiempo y que, además, son la fuente del recrudecimiento y cronicidad de los conflictos que terminan minando las democracias por dentro.

\section{Los medios de comunicación en el ciclo de vida de los conflictos}

Los conflictos son procesos sociales que involucran diferentes dimensiones de las relaciones humanas; tienen causas estructurales, históricas, pero también se alimentan de percepciones y valoraciones erróneas o falsas; se agudizan con acciones de fuerza y ruptura de la comunicación, los cuales marcan hitos de escalamientos que suelen conducir a periodos de crisis donde muchas veces está presente la violencia. Luego estos son seguidos por un periodo de negociación y desescalamiento y terminan en acuerdos, pactos o mesas de negociación. En muchos casos los conflictos no resueltos recrudecen y vuelven a encenderse para convertirse en conflictos cíclicos, como el conflicto con los campesinos sembradores de coca en los valles de la selva alta del Perú. En el tiempo, conflictos como este se convierten en conflictos crónicos como el caso internacional de las fábricas papeleras en la frontera uruguayo-argentina.

El hecho es que los conflictos no se definen por los estallidos de violencia sino que tienen un periodo de maduración y un proceso de reencauzamiento que Galtung ha denominado el "ciclo de vida de los conflictos" en el que las partes no se ponen de acuerdo, pues tienen intereses contrapuestos. Como en todo proceso social, existen márgenes para la prevención, que según Galtung "tiene[n] como objetivo 
transformar la existencia de intereses incompatibles entre las partes en otros positivos para todos los implicados" (Grupo Transcend 2006), buscando que los conflictos se transformen en procesos de desarrollo y cambio social. El siguiente gráfico puede dar una imagen de cómo es el ciclo de vida clásico de un conflicto:

\section{Rol de los medios en el surgimiento de los conflictos}

A continuación, analizaremos los diferentes roles que los medios vienen cumpliendo cuando abordan los conflictos, cuando estos están en su fase inicial o latente, precisamente en el momento donde su abordaje y trans-

\section{Gráfico 1}

Ciclo de vida de los conflictos

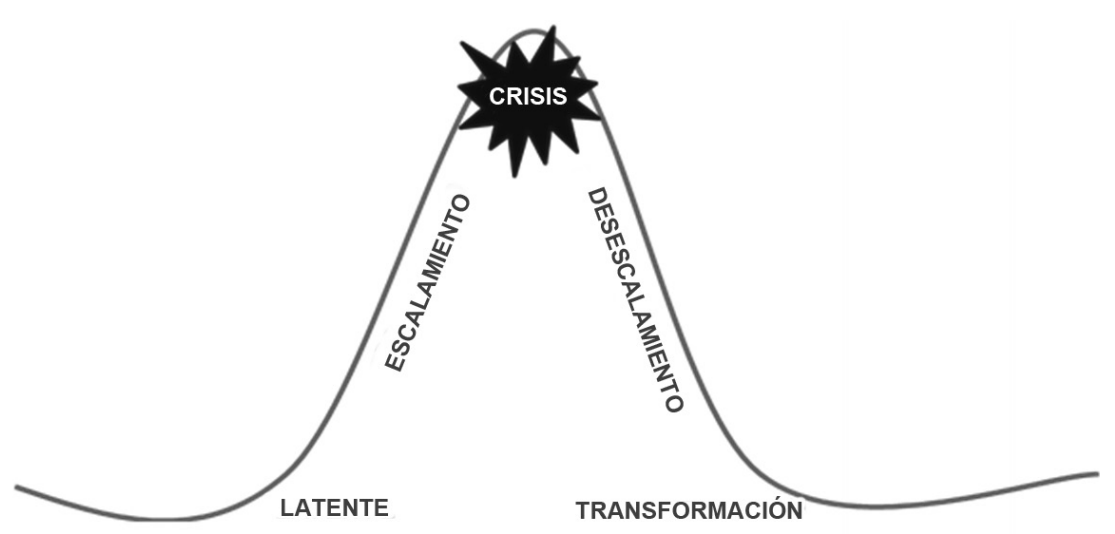

En los ámbitos local, regional y nacional los medios dan visibilidad a los conflictos; participan en todos los procesos, al inicio, durante y después de las crisis; y muestran los acuerdos. Los medios tienen, pues, un rol decisivo que, a nuestro juicio, afecta el curso de los acontecimientos, contribuyendo al enfrentamiento entre las partes. Pero, al mismo tiempo, pueden jugar un rol preventivo para evitar el escalamiento o separar a las partes durante las crisis y aportar en la transformación de los conflictos. formación son más oportunos y menos costosos (gráfico 2).

Los medios cumplen un papel clave para construir un relato sobre los acontecimientos de la vida pública nacional de cada país; sin su cobertura es muy difícil que los ciudadanos se informen de la existencia de los conflictos. En palabras de Mander, "[...] los medios nos brindan historias de conflictos cotidianamente, haciendo que los conflictos sean parte de nuestra dieta diaria cultural" (Mander 


\section{Gráfico 2}

Roles de los medios en la fase latente de los conflictos

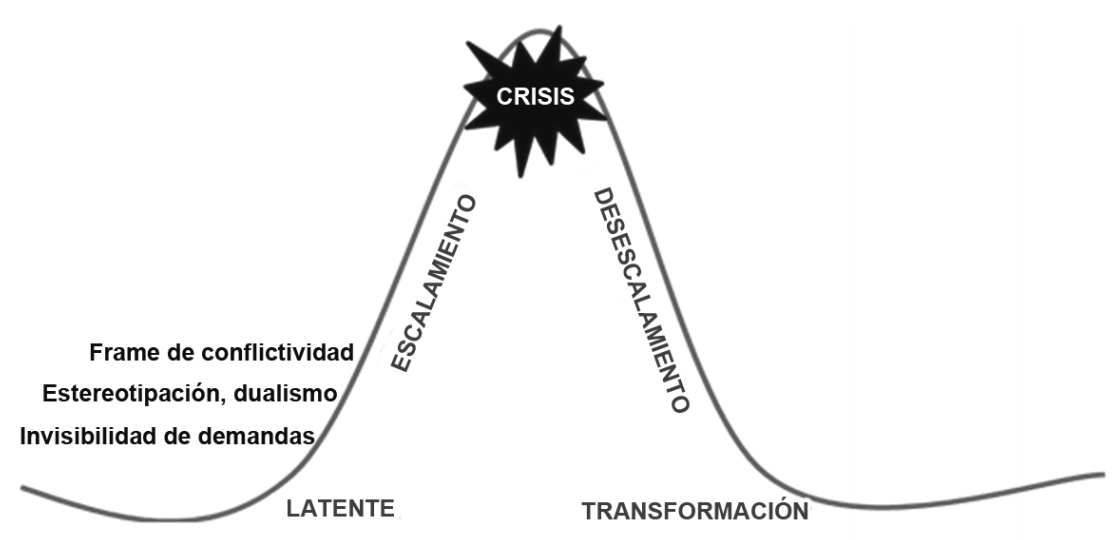

1999). Asimismo, los decisores, sean autoridades, funcionarios o la clase política en general, también se informan a través de los medios, y gracias al seguimiento que hacen sus gabinetes de prensa, incluso toman conocimiento de los hechos antes que sus propios sistemas de inteligencia. En pocas palabras, dan existencia pública a los conflictos.

Como han analizado varios autores, los medios construyen una agenda y en ese proceso suelen excluir o priorizar unos acontecimientos sobre otros, por razones de rating, de presión política o económica, por posiciones ideológicas o por el lobby de los gabinetes de prensa de las empresas. Pero la decisión acerca de qué conflictos deben ser visibilizados y cuáles no responde a una trama compleja de relaciones políticas, económicas y sociales de las que forman parte los medios.

Diversos investigadores coinciden en que los medios suelen dar visibi- lidad pública cuando los conflictos están en su etapa de crisis y las pérdidas humanas, así como los daños materiales son significativos. Torrico (2009) coincide con esta posición luego de analizar los eventos del 2003, 2004 y 2005 en Bolivia, señalando que "[...] no todas las manifestaciones de la conflictividad llegan a conocimiento de los públicos y algunas de las que sí lo hacen reciben más esmero que otras. En esa lógica, tienen más probabilidad de aparecer en las noticias los hechos que generan consecuencias o impactos colectivos". El tiempo mediático de cobertura de un conflicto también puede amplificar las posibilidades de solución y de mediación o de cambio de rumbo hacia procesos de negociación; pero cuando los medios dan visibilidad solo a las crisis, estas opciones disminuyen, especialmente en la fase inicial del conflicto, cuando es más sencillo generar procesos de diálogo y estos son menos costosos. 
Sin embargo, a nuestro juicio, la visibilidad que otorgan los medios al inicio de los conflictos es clave para su prevención temprana. Se requiere un diagnóstico acertado de la naturaleza y las causas de los conflictos; sin esta comprensión es muy difícil generar soluciones que satisfagan a ambas partes. Asimismo, cuando se interviene de manera temprana en los conflictos es más factible generar procesos de diálogo, pues al no mediar violencia entre las partes se generan más posibilidades de construir la confianza que es la base de los acuerdos.

En un reciente estudio encontramos que los medios locales no realizan un seguimiento continuo de los conflictos y no llegan a construir un relato estructurado y coherente. Algunos acontecimientos clave están ausentes, aparecen en un medio y en otro no. Además, no hay contrastación de las fuentes ni investigación periodística; las declaraciones y afirmaciones de los voceros quedan flotando como medias verdades, sin buscar la respuesta o aclaración de la otra parte, dando como resultado que los ciudadanos tengan una interpretación confusa e incompleta de los hechos, así como de la naturaleza, las causas y los contextos de los conflictos. Así, se torna difícil una toma de posición informada y coherente que pueda explorar salidas oportunas cuando el conflicto está en estado latente y es más viable su solución (Macassi y Subauste 2009).
De otro lado, como señala Entman (1993), los medios no solo relatan las noticias, enmarcándolas (frames), sino que le dan forma social al relato. Definen el problema, atribuyéndole una causalidad; emiten juicios, estereotipan a los actores y orientan los cauces de solución. En otras palabras, los medios definen la "imagen pública" de los conflictos influyendo ciertamente en su evolución, "[...] pueden funcionar selectivamente, para acelerar, desacelerar, clarificar o redefinir los conflictos sociales" (Strohm 1999: 60).

\section{Rol de los medios en el escalamiento de los conflictos}

Cuando las amenazas verbales recrudecen, la comunicación se corta y las acciones de fuerza empiezan a reemplazar las palabras, estamos frente a un proceso de escalamiento. En esta fase los medios ponen mayor atención en los conflictos que en la anterior; precisamente, es en esta etapa cuando los medios muestran también un gran desconocimiento sobre los conflictos sociales.

La manera como ingresan los conflictos en la agenda pública influye mucho en el curso de acción de estos, de allí el esfuerzo de autoridades, empresas y organizaciones por tener injerencia en el enmarcamiento que los medios hacen de los conflictos, como 


\section{Gráfico 3}

Roles de los medios en la fase de escalamiento de los conflictos

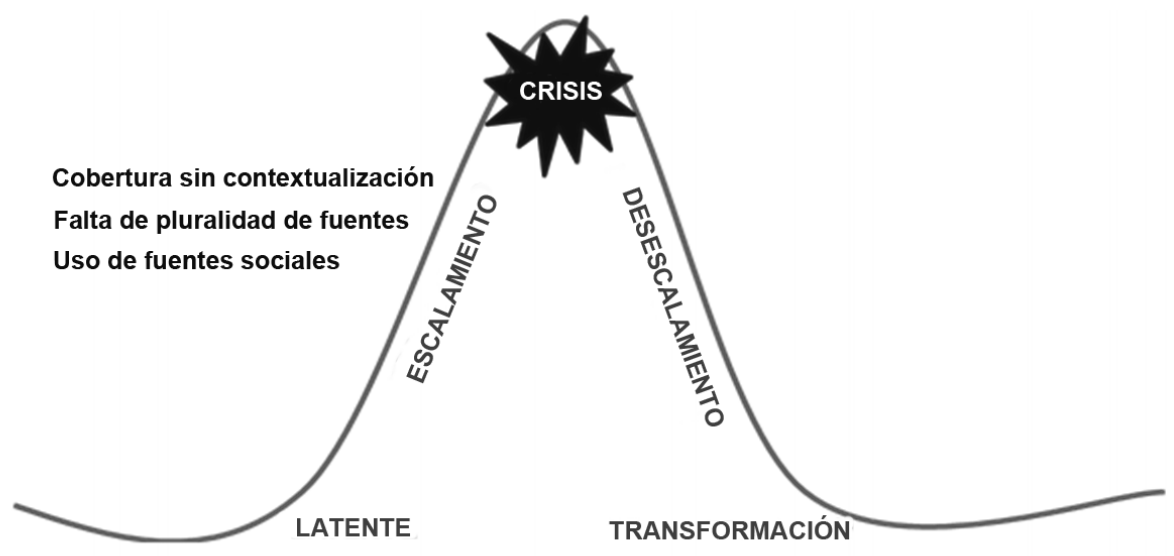

sucedió con la ocupación pacífica por los campesinos cocaleros de las instalaciones de la hidroeléctrica de San Gabán, en Puno, en el 2004, para solicitar el uso del teléfono con el fin de comunicarse con las autoridades de Lima y pedir ser incluidos en el programa de desarrollo alternativo (SER 2004). La cobertura de los medios locales y su posterior rebote en los medios nacionales hicieron referencia a una "toma de la hidroeléctrica", aludiendo a que sectores afines al grupo terrorista Sendero Luminoso estaban detrás del hecho. En el relato se dejó de lado la voluntad de diálogo e inclusión que había motivado la movilización campesina. A pesar de los esfuerzos del alcalde por esclarecer la finalidad de dicha movilización, enviando incluso una carta abierta al diario de mayor circulación nacional, primaba la imagen de que se trataba de narcotraficantes sobre la de campesinos que demandaban y reclamaban por formalizarse y ser incluidos en los programas sociales.

Cuando se dan conflictos y escalan las acciones de fuerza, los medios recurren, en primer lugar, a las fuentes oficiales, que son las que tienen más a la mano, pero no siempre son las más confiables. Muchos de estos voceros se basan en información de inteligencia, generalmente sesgada desde una óptica de guerra enfocada en identificar a los posibles enemigos; por lo tanto, las primeras declaraciones de las autori- 
dades suelen ser beligerantes, buscando la deslegitimación de las demandas y el desprestigio de los interlocutores, lo cual no esclarece el conflicto, dificulta el diálogo con las partes y posiciona negativamente aún más a los sectores radicales. Así ocurrió en el conflicto entre la empresa Río Blanco y los pobladores de Ayabaca y Carmen de la Frontera (Huancabamba), de la región Piura, que habían convocado a una consulta ciudadana el 2008 para votar por la viabilidad o no del proyecto minero. Los medios nacionales recurrieron a las autoridades del sector de Energía y Minas, pero durante las semanas que duró el conflicto los pobladores que convocaron a la consulta no fueron entrevistados en estos medios.

Por cierto, en muchos conflictos los medios no desarrollan un balance informativo, pues suelen centrarse en una de las partes y deslegitiman a las otras. En la medición realizada por Meneses (2007) sobre el conflicto entre Sucre y La Paz, en el 2007, respecto de la ubicación de la sede de gobierno, encontró que el 78 por ciento de las noticias solo presentaban la posición de una de las partes sin la respuesta $o$ posición de la otra.

En la intervención en conflictos, uno de los elementos clave es la participación de las partes de manera equitativa; cualquier inequidad rompe la confianza, fortalece las posiciones de confrontación y alimenta las salidas de fuerza. Al no hacer los medios una cobertura pluralista, simplemente abonan en su recrudecimiento.

Tan importante como la pluralidad es el marco cultural de las partes en conflicto. Sin una adecuada comprensión de estas variables, fracasan los esfuerzos por generar diálogos y acercamiento entre las partes. A raíz de las movilizaciones y la toma de carreteras de los grupos indígenas amazónicos peruanos durante el 2009, para la anulación de los decretos legislativos que los afectaban, los medios de comunicación se centraron en los desencuentros de los procesos de diálogo entre el líder indígena Alberto Pizango y el presidente del Consejo de Ministros Yehude Simon. La cobertura abordó los desacuerdos, las declaraciones, los insultos y las amenazas entre los interlocutores, pero no contextualizó la cosmovisión y la cultura de los pueblos amazónicos, sin los cuales no era posible entender la prioridad vital que para ellos tenía el territorio y la vida comunitaria colectiva. Ellos percibían que las nuevas leyes, que no habían sido consultadas, amenazaban ambas dimensiones y estaban dispuestos a defender con su vida esos principios ordenadores de su identidad. Semanas después la muerte de 23 policías y una decena de pobladores fue resultado de no haber entendido estos principios culturales ordenadores; por eso, coincidimos con la posición del Department for International Development (DFID), cuando afirma que en la medida en que los medios 
muestren "[...] la comprensión de la cultura y el contexto del conflicto, de eso depende que los conflictos puedan transformarse" (2000: 22).

Ciertamente, los medios muchas veces asumen un rol pasivo frente a las noticias y terminan por convertirse en altavoces de la violencia. Un caso ejemplar fue el papel que jugaron los medios en las acciones de violencia en Cochabamaba el 2007, donde se limitaron a dar tribuna a las amenazas de los voceros de "los jóvenes por la democracia", dando cobertura a las acciones de fuerza que se preparaban de cara al ultimátum dado para que los campesinos desalojen la ciudad (Torres 2007: 21). Bajo la premisa de que los medios solo son una faja de transmisión de los sucesos en la sociedad, no buscaron cuestionar ni alertar sobre el desenlace violento que el ultimátum traería consigo, fungiendo de amplificadores de la violencia sin medir las consecuencias al agudizarse la crisis, al punto de cobrar varias vidas en los días siguientes.

Sin embargo, los actores sociales y políticos actúan frente a los conflictos calculando la repercusión que sus acciones o declaraciones pueden tener en los medios. Como lo sostuvimos en otra ocasión (Macassi 2002), cuando los medios no cubren los conflictos, especialmente los locales, las autoridades "no toman cartas en los asuntos" o envían representantes sin capacidad de decisión; en cambio, cuando los conflictos estallan y existe presión pública y mediática, las autoridades intervienen decisivamente. Conscientes de ello, las partes de menor poder o las interesadas en la solución de sus demandas, muchas veces realizan acciones de fuerza para atraer la atención de los medios y con ello "construir agenda mediática" que promueva la participación activa de las autoridades en el conflicto, tal como ocurrió con la cobertura de la toma del aeropuerto durante el paro de productores arroceros en la región amazónica de San Martín el 2002. En esta ocasión, la toma provocó una inmediata reacción del Gobierno, que hasta entonces no había hecho esfuerzos significativos para su solución.

\section{Rol de los medios en los periodos de crisis de los conflictos}

Cuando la comunicación se rompe y las partes se encuentran enfrentadas, con la firme convicción de que la fuerza es la única salida para lograr sus aspiraciones, estamos frente a un momento de crisis, sea esta mediadas por la violencia o no. Lamentablemente, la mayoría de veces los medios centran su atención en este periodo, y tanto los periodistas nacionales como los corresponsales de prensa extranjeros recién acuden para cubrir los acontecimientos. A continuación analizaremos el rol de los medios en esta fase: 


\section{Gráfico 4}

Roles de los medios en la fase de crisis de los conflictos

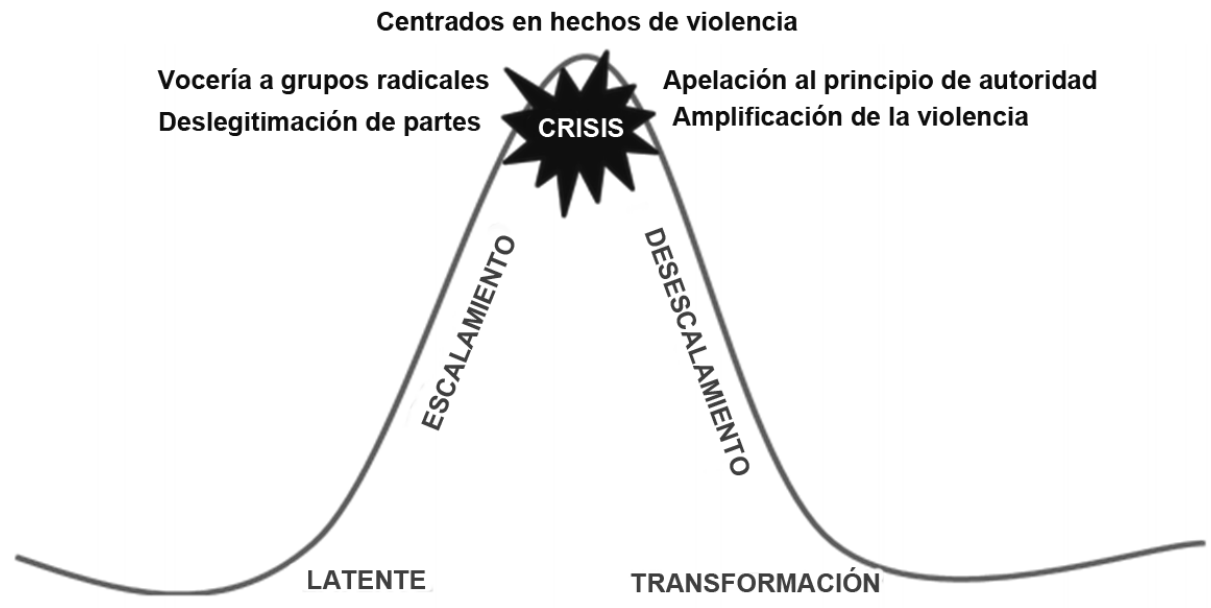

Por otro lado, los medios no siempre pecan por omisión, sino que muchas veces militan a favor de una de las partes, rompiendo no solo el principio de objetividad, sino también los de imparcialidad y tolerancia. Especialmente durante las crisis, muchos medios suelen incentivar las movilizaciones y defender acérrimamente las causas, sin realizar periodismo de investigación. En Bagua, región amazónica del Perú, poco después de un cruento desalojo de una carretera donde varios policías e indígenas habían muerto, la emisora radial La Voz de Bagua informó sobre una treintena de indígenas muertos, mostrando el desalojo como una masacre. Pero la verdad era otra: habían muerto diez indígenas y un número mayor de policías. Sin embargo, esta noticia "en caliente", sin ser corroborada, llegó

a oídos de otro grupo de indígenas que rodeaban la Estación $\mathrm{N}^{\circ}$ 6, quienes desarmaron a los policías dando muerte a más de una docena de estos en represalia por la supuesta masacre. Si bien la emisora fue cerrada ilegalmente por el Gobierno, los medios no tuvieron cuidado de abordar y calificar los hechos de manera adecuada. Caso parecido sucedió con la Radio Televisión Libre des Mille Colines de Ruanda, cuya prédica, sin medir sus consecuencias, influyó para que se produzca el genocidio de 800 mil personas, hecho sucedido de abril a junio de 1994 (Metz noviembre-diciembre de 1997).

Así, el lenguaje empleado por los medios para describir a los integrantes de una de las partes en conflicto es clave, pues muchas veces los estereotipan como delincuentes, terroristas 
cocaleros o les atribuyen condiciones que deslegitiman sus demandas al caracterizarlos como manipulables, sin instrucción, etcétera. Acertadamente, Dell'Oro (2008) lo etiqueta como "el discurso del bien y del mal", cuando analiza la respuesta gubernamental a la huelga del campo en Argentina, que se aplica también al tono confrontacionista e intolerante con que muchos gobiernos tratan de manejar las crisis, cuando lo que consiguen es generar una mayor acumulación de sentimientos negativos y resentimientos que suele ser uno de los ingredientes de la violencia.

Por lo expuesto, enmarcar hechos violentos es riesgoso y puede tener consecuencias lamentables, como bien lo describe Yuri Torres cuando investigó sobre el conflicto sucedido en Cochabamba en enero del 2007. En este caso, los medios catalogaron a las víctimas: a unas les dieron categoría de "héroes", mientras que a las otras las trataron como víctimas anónimas. Con ello, "[...] voluntaria o involuntariamente, de manera decisiva refuerza[n] algunas estigmatizaciones que anidan en el imaginario popular" (Torres 2007: 19). Así, abonan en la polarización política pero también en la social y la racial, que marcaron las acciones de violencia entre campesinos y jóvenes urbanos en un momento de alta conflictividad social. A la misma conclusión llegó la periodista Jacqueline Fowks (2009) al analizar los titulares de los diarios durante la cri- sis de junio del 2009 en Bagua, cuando afirma que "[...] algunos medios aluden a policías 'asesinados' y nativos 'fallecidos', hay que agregar que otros medios sensacionalistas titularon de 'caníbales' y 'genocidas' a los nativos por el ajusticiamiento de una decena de policías".

En lugar de generar distensión, este tipo de cobertura mediática refuerza la contraposición, fomenta los resentimientos y la sensación de exclusión de la parte más vulnerable, y alimenta el fuego para el recrudecimiento del conflicto, generando un efecto de amplificación de la violencia.

\section{Rol de los medios en el desescalamiento de los conflictos}

En el momento en que cesan las acciones de violencia, las partes se separan y deponen las medidas de fuerza o aceptan procesos de diálogo, es cuando los medios pueden contribuir a la solución del conflicto, al generar distensión y evitar que la violencia resurja. Deben tener en cuenta que los conflictos son muy inestables y no se requiere de mucho para que las hostilidades se reanuden y se rompa la comunicación, que generalmente ha costado daños materiales y a veces vidas humanas. Sin embargo, no todos los medios lo ven de esta manera, algunos no comprenden el ciclo de vida de los conflictos y favorecen su reescalamiento. 


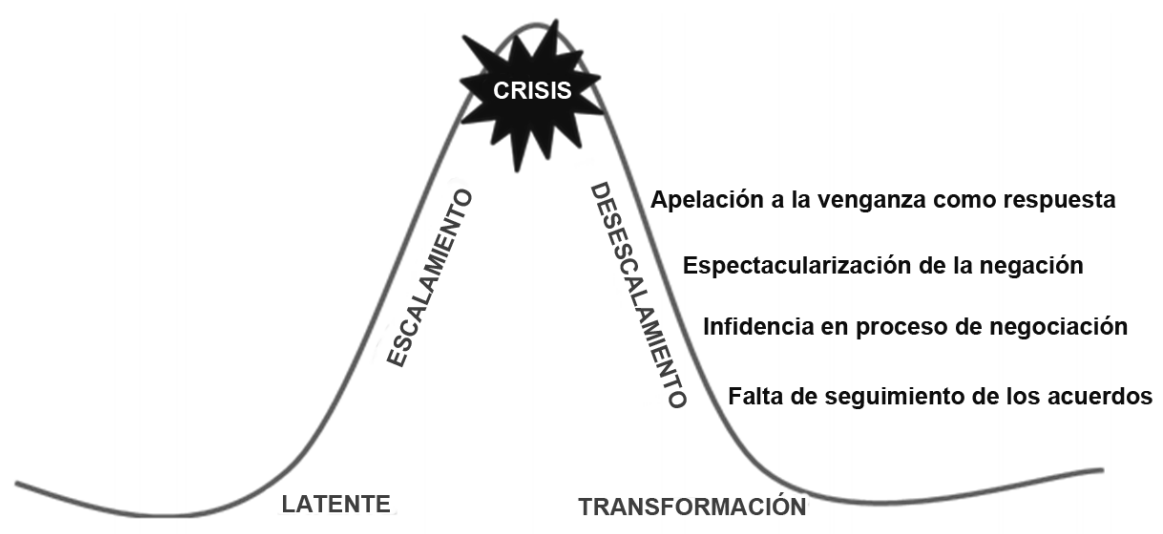

Un caso muy controvertido fue el rol que cumplió del diario El Comercio, el más importante del Perú. Ocurrió cuando en acción valiente, el general Jordán decidió rendirse y abortar el desalojo del puente Montalvo en Moquegua, región al sur del Perú, evitando con ello una alta cifra de muertos civiles. El levantamiento masivo fue remontado y fueron liberados los policías tomados como rehenes. El diario mencionado publicó un editorial en el cual afirmó: “[...] la autoridad jaqueada y literalmente por los suelos y el Estado de derecho peligrosamente desvirtuado con lo que se sienta un peligrosísimo e intolerable precedente" (El Comercio 18 de junio del 2008); además, exhorta a una acción de fuerza que resane la situación, afirmando que "[...] la grave situación requiere de explicaciones y soluciones urgen- tes, para restaurar el imperio de la ley, el orden y la autoridad". Por cierto, la investigación posterior demostró que la operación estuvo mal diseñada y dirigida desde Lima, lo cual creó la situación insostenible, en la que pocos policías se vieron rodeados por tres mil pobladores, y una nueva incursión policial, con "todo el peso de la ley", hubiera generado una respuesta incontrolable de parte de la población. Meses después, bajo la premisa de restaurar el principio de autoridad a todo costo, murieron 34 personas, entre policías y civiles, en los sucesos de Bagua descritos en el acápite anterior.

Las malas decisiones no solo son monopolio de los editores periodísticos, también los gabinetes de prensa de los ministerios cometen inmensos errores, como fue el caso del spot televisivo difundido por el Ministerio 
del Interior peruano después de los sucesos de Bagua, mostrando a los policías muertos con las heridas abiertas, estereotipando a los indígenas de extremistas, acusándolos de ser títeres de gobiernos extranjeros. Dicho spot generó mucho resentimiento entre los indígenas más jóvenes, que sintieron que el Gobierno central deslegitimaba históricamente sus demandas. No cabe duda de que una comunicación de este tipo puede generar un resurgimiento del conflicto, pero al mismo los medios que lo difunden se ven en un dilema ético, como fue el que experimentó la emisora Radio Cutivalú, del norte del país, cuando el Gobierno intentó comprar un espacio publicitario para transmitir un spot contra la consulta popular, a la que describía como ilegal. El director de la radio optó por no firmar el contrato, con el argumento de que dicho spot faltaba a la verdad e iba contra los principios y el análisis que había hecho la radio sobre el conflicto. Por cierto, no volvió a recibir publicidad estatal; tampoco lo hizo la Coordinadora Nacional de Radio (CNR), a la cual pertenecía.

El proceso de diálogo que se genera luego de la fase de crisis, es otro de los puntos de inflexión en el ciclo de vida de los conflictos. Se trata de un delicado proceso de construcción de confianza entre las partes, identificando los puntos en común y explorando soluciones alternativas; sin embargo, se trata de un camino sinuoso plagado de aristas, avances y retrocesos, pues debido a la violencia las partes se han distanciado y confrontado; por ello, la presencia de los medios en los procesos de negociación debe ser muy bien pensada. Coincidimos con Spadoni et al., cuando afirma:

[...] la presencia directa de los medios en el ámbito de la discusión puede generar efectos perversos para la construcción de la confianza. Estando directamente en el lente del público, los participantes del proceso suelen estar menos dispuestos a pensar en soluciones integradoras. "Actuando" para la cámara, los actores tienden a tomar posiciones menos flexibles para lucir ante sus bases como representantes fuertes y potentes ante los enemigos (s/f: 12).

Ciertamente, una infidencia filtrada por la prensa puede romper los procesos de negociación, que tanto esfuerzo cuestan, y volver a la situación de beligerancia anterior. Diversos procesos de negociación lo pueden atestiguar.

Lamentablemente, en la etapa de declive de los conflictos los corresponsales de la capital y de los medios internacionales suelen volver a sus lugares de origen, pues la paz y los acuerdos no venden; por ello, los medios no les prestan el mismo interés que a las crisis y los eventos luctuosos.

Para graficar este comportamiento, se puede recordar que un año después de los sucesos del puente Montalvo, en Moquegua, mencionado líneas arriba, la mayoría de los acuerdos alcanzados en la mesa de negociación que se instauró no se habían cumplido, y los medios, incluso los locales, no mos- 
traron interés en este hecho. No es de extrañar que muchos conflictos recrudezcan y otros nuevos se monten sobre conflictos anteriores que no fueron debidamente resueltos, generándose una espiral de escalamiento que afecta la gobernabilidad local, regional y nacional.

\section{Roles de los medios como preventores y transformadores de los conflictos}

A pesar de las enormes dificultades que tienen los medios para comprender los conflictos y desarrollar un periodismo preventivo, algunos medios locales han realizado tareas encomiables para acercar a las partes, convirtiéndose en espacios para el diálogo, en puentes culturales entre las poblaciones excluidas y los gobernantes. Asimismo, los medios han canalizado demandas y las han visibilizado frente a la autoridad. Sin embargo, estas experiencias no se han constituido en prácticas habituales o protocolos de intervención y la forma de abordar los conflictos difiere sustancialmente de un periodista a otro de un mismo medio.

En mi opinión, los medios cumplen un rol muy importante en la prevención de los conflictos. Diez son los principales puntos en los que los medios deben enfocarse al abordar los conflictos:

1. Visibilizar las demandas y las necesidades y buscar la interlocución con las autoridades y las partes involucradas en su solución. De cierta manera, los medios podrían servir de sistemas de alerta temprana para que los conflictos no escalen y pasen a la fase de crisis.

2. Buscar que ambas partes den su versión, apostar a que la información sobre el conflicto sea lo más plural posible, evitando recoger solo la posición oficial de las autoridades o de las empresas.

3. Enmarcar los conflictos, a partir del análisis de las causas y sus orígenes, dentro del contexto cultural, en lugar de enfocarse en la confrontación y las acciones de violencia, dejando de lado las posiciones y discursos confrontativos de las partes.

4. Apostar a que los terceros -los afectados directa o indirectamente por el conflicto- también opinen y propongan soluciones, evidenciando la pluralidad de las fuentes y la polífonía de actores. Involucrar a los stakeholders es una estrategia que ha demostrado ser muy positiva para distender los conflictos y no permitir que las partes decidan por el resto de la sociedad.

5. La búsqueda de puntos en común y consensos reales debe ser una tarea prioritaria para avanzar en acuerdos sostenibles que satisfagan a las partes.

6. Dar visibilidad y presencia pública a los liderazgos propositivos y proclives al diálogo. 
7. Los periodistas deben esforzarse por acercar a las partes, construir confianza entre ellas, en lugar de enfatizar las diferencias o estigmatizar ("cocaleros", "patronales", "manipulables", "extranjeros") o deshumanizarlos ("hienas", "diablos", "robots"); podrían, además, identificar los aspectos que los unen y los acuerdos que posibiliten procesos de diálogo.

8. En la medida en que convocan a otros actores -"terceros" especialistas- los medios pueden explorar soluciones alternativas, hacer que las posiciones que enfrentan a las partes se "desenganchen", presentando casos similares que fueron resueltos o ángulos humanos de los problemas que permitan la mutua comprensión.

9. Los medios pueden desempeñar un papel de garantes o vigilantes, creando consensos en torno a los acuerdos, haciéndoles seguimiento, presionando a las autoridades para que se cumplan o también pueden generar mecanismos de diálogo y solución cuando los acuerdos no se cumplen.

10. Asimismo, pueden cumplir una función clave para transformar las demandas surgidas en los conflictos en demandas ciudadanas, con el fin de generar procesos de desarrollo, que es a lo que finalmente apunta la transformación de los conflictos.

El siguiente cuadro clarifica los diferentes nuevos roles que los medios podrían desarrollar para favorecer soluciones dialogadas y transformadoras de los conflictos sociales:

Nuevos roles de los medios en el ciclo de vida de los conflictos sociales

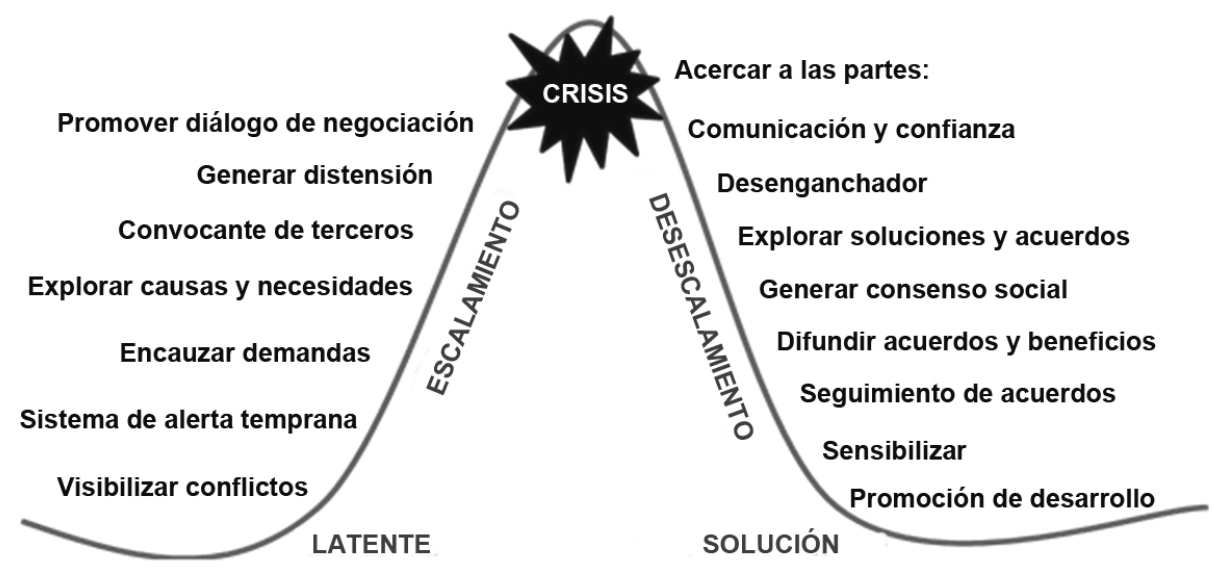




\section{Bibliografía}

Dell'Oro, Jorge (2008). “Quién comunicó mejor? ¿El campo o el Gobierno?". Elecciones.net. Portal Político Iberoamericano. <http://elecciones.net/opinion/?numero $=49$ $7 \&$ show $=1 \& \mathrm{p}=\mathrm{d}>$. [Consulta: $29 \mathrm{de}$ diciembre de 2010.]

DFID (2000). Working with the media in conflicts and other emergencies. Londres.

Entman, Robert (1993). "Framing: Toward clarification of a fractured paradigm". Journal of Communication 43 (4). Autumn, pp. 51-58.

Fowкs, Jacqueline (6 de junio del 2009). "La palabra de los nativos no sirve en los medios". Notas desde Lenovo. $<$ http://notasdesdelenovo.wordpress.com/2009/06/06/la-palabrade-los-nativos-no-sirve-en-los-me$\operatorname{dios} />$.

Grupo Transcend (2006). “Trascender los conflictos. La perspectiva de Johan Galtung". Futuros, Año 13, Vol. IV. <http://www.revistafuturos.info/futuros13/trascender_conflictos.htm>.

Macassi, Sandro (abril-junio del 2002). "Conflictos sociales y espacio público: Responsabilidad de los medios en la conformación y escalonamiento de los conflictos". Contribuciones. Año XIX, núm. 2 (74) Buenos Aires: Fundación Konrad Adenauer.
Macassi, Sandro y Enrique Subauste (2009). "Principales hallazgos del estudio sobre el tratamiento informativo y gestión periodística en los conflictos medioambientales". Mimeo. Lima: Asociación Calandria.

MANDER, Mary (1999). Framing Friction, Media and social conflict. Chicago: University of Illinois Press.

Meneses, Óscar (2007). "Páginas en rojo sobre el cabildo paceño". Lazos, medios en conflicto. Año 2, núm. 4. La Paz: Fundación UNIR.

Metzl, Jamie (noviembre-diciembre de 1997). "Information intervention, when switching channels isn't enough". Foreign Affairs. Vol. 76, núm. 6.

Servicios Educativos Rurales (2004). "Villa de San Gabán: Cronología de los hechos". <http://www.ser.org. pe/index.php?option=com_content \&task=view\&id=185\&Itemid=126>.

Spadoni, Eliana; Lumerman, Pablo y Julián Portilla (s/f). "La mesa de diálogo colaborativo por las 2000 hectáreas de Puerto Iguazú: Conflicto de tierras y gobernancia local". Fundación Cambio Democrático. Buenos Aires. <http:// www.cambiodemocratico.org/archivos/MESA\%20de\%20DIALOGO. pdf>.

Sтroнm, Susan (1999). "The black press and the black community: Los Angeles Sentinel's coverage of 
the Watts Riots", en Mander, Mary. Framing friction, media and social conflict. Chicago: University de Illinois Press.

Torres, Yuri (2007). "11 de enero en Cochabamba: De los medios, miedos y otros demonios". Lazos, medios en conflicto. Año 2, número 4. La Paz: Fundación UNIR.
Torrico, Erick (2009). “Los medios de comunicación masiva en conflicto: Reflexiones sobre el papel del periodismo en la tensa situación boliviana". Contratexto Digital. Año 6, núm. 7. Lima: Universidad de Lima. <http://www.ulima.edu.pe/ Revistas/contratexto/v7/PDFs/01ErickTorrico.pdf $>$. 